\title{
Estimated impact and cost-effectiveness of rotavirus vaccination in Senegal:
}

\section{A country-led analysis}

Abdou Diop [PharmD, MSc $]^{1}$, Deborah Atherly [BScPharm, PhD $]^{2 *}$, Alioune Faye $[\mathrm{MD}]^{3}$, Farba

Lamine Sall $[\mathrm{PhD}]^{4}$, Andrew D. Clark $[\mathrm{MA}]^{5}$ Leon Nadiel $[\mathrm{MD}]^{6}$, Binetou Yade ${ }^{7}$, Mamadou Ndiaye $[\mathrm{MD}]^{7}$, Moussa Fafa Cissé $[\mathrm{MD}]^{8}$, Mamadou Ba $[\mathrm{MD}]^{8}$

Affiliations:

(1) Independent Consultant for PATH, Dakar Senegal

(2) PATH, Seattle WA

(3) Fatick Hospital, Senegal

(4) WHO, Dakar Senegal

(5) Department of Health Services Research and Policy, London School of Hygiene and Tropical Medicine, London, United Kingdom

(6) Hospital Principal, Dakar Senegal

(7) Ministry of Health, Senegal

(8) Albert Royer Children's Hospital, University Cheikh Anta Diop

Corresponding author Deborah E Atherly, PhD at: PATH, 2201 Westlake Ave, Seattle, WA Phone: 206-285-3500; Fax: 206-285-6619. Email: datherly@path.org 


\section{INTRODUCTION}

Recent case-control studies conducted in Africa have confirmed that rotavirus is the leading cause of acute, moderate to severe diarrhea among children under 5 years of age presenting at healthcare facilities. [1] This supports the regional rotavirus surveillance coordinated by the African Regional Office of the World Health Organization (WHO), which reports that approximately $38 \%$ of cases reporting to hospital with acute diarrhea were rotavirus-positive. [2] Rotavirus is estimated to be responsible for about $5 \%$ of all deaths in young African children. [3]

In the area of child health, many life-saving interventions, such as oral rehydration therapy and micro-nutrient supplementation, that prevent and manage diarrhea are available and have been proven to be effective [5]. Unfortunately, utilization and coverage of these inexpensive and effective interventions are low in most countries in Africa [6, 7], although efforts are underway to improve uptake. Furthermore, strategies such as improving water quality and sanitation, food quality, and hygiene are generally long-term and linked to socioeconomic empowerment and development of communities. In addition, these strategies have not had a great impact in reducing the incidence of rotavirus diarrhea [3]. Rotavirus immunization, on the other hand, is available and has been shown to have a dramatic effect on reducing diarrheal hospitalizations, [8] diarrheal deaths, $[9,10]$ and to be cost-effective[11-16]. Thus, since 2009, WHO has recommended the introduction of rotavirus vaccination into the national Expanded Program on Immunization (EPI), particularly in countries with high diarrheal mortality. [17] In addition, Gavi, the Vaccine Alliance, (GAVI) has prioritized support for 
22 rotavirus vaccine to low-income countries, and many countries in the African region are

23 introducing rotavirus vaccine. [18]

Currently, two rotavirus vaccines are available commercially and are pre-qualified by

25 WHO for procurement by UNICEF. [3] A pentavalent, reassortant vaccine containing the common human rotavirus antigens, RotaTeq ${ }^{\mathrm{TM}}$ (Merck Research, Whitehouse, Pennsylvania,

27 USA) is available as an oral, 3-dose, live attenuated vaccine. The monovalent rotavirus vaccine,

28 Rotarix $^{\mathrm{TM}}$ (GlaxoSmithKline Biologicals, Rixensart, Belgium) based on a human rotavirus strain, is

29 licensed as an oral, 2-dose, live attenuated vaccine. Both vaccines are expected to provide similar benefits at similar cost for low-income countries. So, for simplicity, just one product--the

31 monovalent vaccine, was evaluated.

In addition to the substantial morbidity, there is growing evidence of the economic burden created by diarrheal disease [19-24]. In particular, where resources are limited, such as

34 in sub-Saharan Africa, it is critical for national authorities to be informed of the economic 35 implications for their strategic choices. Consequently, cost-effectiveness analysis (CEA) has

36 become an increasingly necessary criterion among other policy issues in new vaccine

37 introduction strategy. This has been addressed by the Pan American Health Organization's

38 (PAHO's) ProVac Initiative in Latin American countries and is now being disseminated under its

39 auspices to other WHO regions [25]. The current initiative was launched in Senegal; the ProVac

40 International Working Group (IWG) is helping to pave the way for better child health (saving

41 lives and preventing diseases) by enabling national decisions-makers to identify and use more

42 consistent and reliable evidence to support the decision-making process regarding vaccines. 
The TRIVAC model, developed by researchers from the London School of Hygiene and Tropical Medicine (LSHTM), is built in Microsoft Excel with support from PAHO's ProVac

47 Initiative and GAVI's Haemophilus influenzae type b (Hib) Initiative. TRIVAC is purposefully

48 designed for use at country level, and allows national teams to perform cost-effectiveness analyses of vaccines for three diseases: pneumococcal, rotavirus, and Hib. Version 2.0 of the model was used for this analysis. The model includes the following categories of input

51 parameters: demographics, burden of disease, vaccine schedule, vaccine efficacy, vaccine costs,

52 health services utilization, and health services costs. Model inputs and their values are shown in

53 Tables 1 - 5. Detailed model structure and methodology have been published previously [26]. outcomes incurred by these populations were estimated under scenarios with and without rotavirus vaccine. Results are reported for one single cohort for the year 2019, when the

57 vaccination program is expected to be fully scaled up, and for 20 cohorts from 2014-2033.

The analysis was conducted from both healthcare system and societal perspectives.

59 Household out-of-pocket costs for direct medical expenses were included in the societal

60 perspective, but non-medical and indirect costs were not included. All costs and health

61 outcomes were discounted at $3 \%$ per year.

\subsection{Demographic data}


65 National data on mortality rates were drawn from Demographic and Health Surveys and

66 Situation Economique du Senegal (Economic Situation of Senegal) reports, [27-29] whereas

67 United Nations Population Division (UNPOP) data were used for births and life expectancy.

68

69

70

71

72

73

74

75

76

77

78

79

80

81

82

83

84

\subsection{Disease burden}

There are no Senegal-specific estimates for incidence of rotavirus gastroenteritis (RVGE), so we assumed a rate of 10,000 per 100,000 in children under 5 , based on the pooled estimate from a global meta-analysis [30]. To estimate RVGE hospitalizations, we assumed an incidence rate of 500 per 100,000 in children under 5 globally, which is consistent with estimates from Kenya [31] and several countries in Latin America [32]. To estimate overall severe RVGE incidence, we divided RVGE hospital incidence (500 per 100,000 per year in children under 5) by the percentage of those with access to care in Senegal. The non-severe RVGE incidence was calculated by subtracting the severe RVGE incidence from the overall incidence of RVGE $(10,000$ per 100,000 in children under 5).

The proportion of diarrheal deaths due to rotavirus was estimated from Senegal-specific and regional surveillance data. [33-37] Estimates from these studies ranged from 26\% to 41\%; $34 \%$ was used as the base-case estimate, and the range was explored in the scenario analysis. Using this proportion, the number of deaths due to rotavirus in children under 5 was calculated by multiplying the diarrheal disease deaths in Senegal for the year 2010 by the proportion attributable to rotavirus. It is estimated that there were nearly 1,000 deaths due to rotavirus in 2010, equivalent to 45 per 100,000 per year [38]. This was adjusted to the year of anticipated 
85 vaccine introduction (2014) by assuming the same percentage of mortality in children under 5

86 would be due to rotavirus over the period from 2010 to 2014.

Senegal is expected to initially introduce the monovalent rotavirus vaccine. The vaccine requires two doses and will be administered within the current EPI infant vaccination schedule. Therefore, DTP1 and DTP2 coverage levels were used as proxies for rotavirus vaccine coverage projections, and were provided by the latest vaccine coverage survey conducted in February

922013 by the Directorate of Preventive Medicine within the Ministry of Health.[39]

An adjustment factor (relative coverage), was applied to the coverage estimates to account for the likelihood that children at the highest risk of dying from rotavirus disease are less likely to be vaccinated. The relative coverage was determined by dividing the DTP coverage

96 in the lowest wealth quintile by the DTP coverage in the entire population. good efficacy against severe rotavirus cases. Data for this analysis in Senegal were based on the large, randomized, controlled trial of the monovalent rotavirus vaccine (Rotarix ${ }^{\mathrm{TM}}$ ) carried out in South Africa and Malawi [40] using 2 and 3 doses of the vaccine. The overall vaccine efficacy in preventing severe RVGE was $61.2 \%$ (95\% confidence interval $[\mathrm{Cl}]): 44 \%$ to $73.2 \%$ ). In preventing severe RVGE among infants who received two doses of vaccine, the overall efficacy of the vaccine was $58.7 \%(95 \% \mathrm{Cl}: 35.7 \%$ to $74.0 \%)$; in those who received three doses, the overall 
105 vaccine efficacy was $63.7 \%$ (95\% Cl: $42.4 \%$ to $77.8 \%)$. In Senegal, the efficacy rate used was the 106 pooled data from both countries at two doses, which corresponds to $58.7 \%$ efficacy $(95 \% \mathrm{Cl}$ :

$107 \quad 35.7 \%$ to $74.0 \%)$.

108 The protective effect of rotavirus vaccines has been shown to decline over time. For 109 most efficacy and effectiveness studies a reduction is reported after one year, and again after

110 two years [41]. Waning vaccine protection was determined in this analysis by comparing

111 second-season efficacy (42\%) against first-season efficacy (59\%) from the pooled Malawi/South

112 Africa clinical trial data. This gives $29 \%$ waning protection per year, calculated as follows: ([59\% $113-42 \%] / 59 \%)$.

$114 \quad 2.6$ Vaccine and systems costs

Vaccine cost per dose includes the vaccine price, handling, and delivery fees. As a GAVI-

116 eligible country in the intermediate co-financing group, Senegal will benefit from support for

117 vaccine; its co-pay agreement starts at $\$ 0.20$ per dose and increases by $15 \%$ annually [42].

118 Handling and delivery fees obtained from GAVI applications are $3 \%$ and $2 \%$, respectively. A

119 wastage rate of $5 \%$ was included in the calculation of vaccine price.

120

Estimates for the incremental systems cost to deliver each dose of rotavirus vaccine

121 were derived from the Senegal Project Optimize study conducted in 2013 for cold-chain costs

122 per dose, in addition to detailed costing work conducted in Ethiopia $[43,44]$. The incremental

123 cost estimate was $\$ 0.50$ per dose, including start-up costs such as training and communication

124 as well as ongoing costs for supervision, cold chain, transportation and supplies. The cost 
125 assumes that the existing immunization program staff in the health facilities were used for the 126 introduction.

\subsection{Health services utilization}

The health delivery system is divided into three major levels of care. The first line of care

129 is provided by facilities called health posts. Services are oriented toward promotional and

130 preventive activities and serve a large proportion of the rural population.

The second line of care consists of health centers and district hospitals. These

132 intermediate-level healthcare facilities provide basic curative healthcare services, including

133 maternal and dental care.

The third line of care is comprised of regional and national hospitals, including teaching facilities. Many medical and surgical specialties such as cardiology, internal medicine, pediatrics, gynecology, neurology, and neurosurgery can be found at these facilities. In order to determine the distribution of visits and admissions for diarrheal disease

138 across health facility levels, we used WHO-CHOICE [45] estimates and local reports [46], then 139 conducted phone interviews with five district public health doctors working in four different 140 regions of Senegal (Fatick, Thies, Diourbel, and Kaolack). (WHO-CHOICE is an initiative that, 141 among other things, identifies healthcare interventions that are most cost-effective.)

142 District and regional hospitals are estimated to provide services to approximately $70 \%$ of 143 severe rotavirus cases, while $20 \%$ are seen in national hospitals, and the remaining cases in 144 lower levels of care. Non-severe cases, by contrast, were seen primarily in health posts and 
145 health centers (75\%), while the remainder were seen in district, regional, and national

146 hospitals.

$147 \quad 2.8$ Health services costs

Government costs per inpatient bed-day and the cost per outpatient visit are available

149 from WHO-CHOICE [47]. Since the additional disease-specific costs are not included in these

150 estimates, for all diseases we inflated CHOICE estimates by $25 \%$ to account for the cost of

151 disease-specific drugs, diagnostics, and procedures. This fraction is based on the fraction

152 reported in a recent South African pneumonia costing study [48]. Household costs were

153 assumed to be equivalent to the percentage of total health expenditure which is out-of-pocket,

154 based on estimates from the WHO Global Health Expenditure Database [49]. In Senegal, 34\% of

155 healthcare expenditures are borne by households. The formula used to estimate the household

156 cost per visit or admission was: [Government cost per case / ( $1-\%$ of total cost borne by

157 households)] - Government cost per case. Household costs included direct medical expenses,

158 but not direct non-medical or losses in productivity.

$159 \quad 2.9$ Sensitivity analysis

Scenario analysis was performed to assess the impact of changes in specific model input

161 values on the cost-effectiveness -- cost/DALY (disability-adjusted life year) averted of rotavirus

162 vaccination. Variables included incidence of disease, mortality, vaccine efficacy, waning

163 protection, vaccine coverage, relative coverage, vaccine systems costs, vaccine prices, cost of

164 healthcare services and percentage discounting. 


\section{RESULTS}

\subsection{Health impact of vaccination}

The outcomes presented in Table 6 reflect the projected health outcomes under scenarios with and without a rotavirus vaccination program. Introduction of rotavirus vaccine in Senegal could result in a reduction of more than 2 million cases of rotavirus and nearly 190,000 DALYs and avert more than 8,500 deaths from 2014 to 2033. Once the program is fully

171 implemented, vaccination is estimated to avert over 80,000 cases and prevent more than 450 172 deaths per year, equivalent to $42 \%$ of all rotavirus deaths.

\subsection{Cost and cost-effectiveness of vaccination}

The healthcare costs with and without vaccination are shown in Table 7. The costs

175 averted due to vaccination are higher from the societal perspective due to the inclusion of

176 household out-of-pocket costs. The cost-effectiveness of rotavirus vaccination is $\$ 92$ and $\$ 73$

177 per DALY averted from the health provider and societal perspectives, respectively (Table 8).

\section{$178 \quad 3.3$ Scenario analysis}

Figure 1 presents the results of varying select model input values on the cost-

180 effectiveness of vaccination. The base case from a provider perspective is $\$ 92$ per DALY

181 averted. Under all scenarios involving the most influential factors, results vary from $\$ 50$ to $\$ 170$

182 per DALY averted-all well below the cost-effectiveness threshold of $\$ 1,040$, the GDP per capita 
183 for Senegal [50]. This suggests that the model results are robust to changes in the value of all 184 major variables.

\section{DISCUSSION}

The results of this evaluation suggest that rotavirus vaccination would be highly cost-

187 effective and would substantially reduce child illness and deaths due to rotavirus in Senegal.

188 The analysis was performed using local data where possible, and relied on regional and global

189 estimates when national data were not available or practical to collect. Limited data on the

190 burden of rotavirus in Senegal were available, but those data were assessed together with

191 national and regional data from other African countries to broaden and strengthen the body of

192 evidence.

Although analyses that project costs and benefits into the future aim to use the best

194 available data to achieve highly valid results, limitations will always be present. Healthcare costs

195 were estimated from WHO-CHOICE; although this is a good source of data in the absence of

196 costs collected directly at the national or sub-national level, future evaluations should seek to

197 incorporate these local costs as they become available. A small sample of local costs gathered

198 from a survey of physicians and facilities were explored within the scenario analysis and the

199 changes observed had little effect on the cost-effectiveness of vaccination. Local data were

200 available on cold-chain systems costs from a recent project in Saint Louis, Senegal. Since cold-

201 chain and related transportation costs are the most significant portion of vaccine systems costs,

202 the local data were valuable in assessing these costs. However, the data were modeled for one

203 region and extrapolated nationally for this analysis. Variations in systems costs were also 
explored in sensitivity analysis and cost-effectiveness results were robust to a doubling of the 205 base case estimate.

Results obtained in this study are consistent with the cost-effectiveness of rotavirus

207 vaccine from previous studies done in many developing country settings worldwide, [14, 16, 51-

208 54] and in particular, consistent with a cost-effectiveness study conducted in Malawi[14]:

209 Vaccine program cost-effectiveness for both perspectives in Senegal would be similarly

210 favorable to results from Malawi, which demonstrated $\$ 74.73$ per DALY averted.

The study was performed by local researchers, with input data and results reviewed and

212 approved by a local group of experts, which contributes to the relevance and validity of the

213 analysis. Engaging local experts in the collection and validation of model inputs and results is

214 very likely to increase the acceptability of the evidence for local policy-makers. This in turn may

215 improve the likelihood that the evidence will be incorporated into decision-making about the

216 adoption and ongoing support of vaccination programs in Senegal.

217 Senegal recently made the decision to introduce rotavirus vaccines with GAVI support.

218 Over time, the country is expected to contribute a greater share of the vaccine price.

219 Eventually, Senegal may graduate from GAVI eligibility and incur the full price of vaccine. As

220 Senegal and other countries take on an increasing share of costs, analyses that elucidate the

221 benefits and costs of new vaccines are likely to become even more relevant to the decision-

222 making process. 


\section{Acknowledgements}

226

We would like acknowledge the financial support provided by the Bill and Melinda Gates

227 foundation through PAHO's Provac International Working Group. We also want to thank Erin

228 Kester and Nathaniel Hendrix for their editorial contributions. 


\section{References}

1. Kotloff, K.L., et al., Burden and aetiology of diarrhoeal disease in infants and young children in developing countries (the Global Enteric Multicenter Study, GEMS): a prospective, case-control study. Lancet, 2013. 382(9888): p. 209-22.

2. WHO, WHO Global surveillance. Wkly Epidemiol Rec, 2013. 88(21): p. 217-23.

3. WHO, WHO Position Paper. Wkly Epidemiol Rec, 2013. 88(5): p. 49-64.

4. Lanata, C.F., et al., Global causes of diarrheal disease mortality in children $<5$ years of age: a systematic review. PLoS One, 2013. 8(9): p. e72788.

5. Munos, M.K., C.L. Walker, and R.E. Black, The effect of oral rehydration solution and recommended home fluids on diarrhoea mortality. Int J Epidemiol, 2010. 39 Suppl 1: p. i75-87.

6. Ram, P.K., et al., Declines in case management of diarrhoea among children less than five years old. Bull World Health Organ, 2008. 86(3): p. E-F.

7. Santosham, M., et al., Progress and barriers for the control of diarrhoeal disease. Lancet, 2010. 376(9734): p. 63-7.

8. Patel, M.M., et al., Real-world impact of rotavirus vaccination. Pediatr Infect Dis J, 2011. 30(1 Suppl): p. S1-5.

9. Richardson, V., U. Parashar, and M. Patel, Childhood diarrhea deaths after rotavirus vaccination in Mexico. N Engl J Med, 2011. 365(8): p. 772-3.

10. do Carmo, G.M., et al., Decline in diarrhea mortality and admissions after routine childhood rotavirus immunization in Brazil: a time-series analysis. PLoS Med, 2011. 8(4): p. e1001024.

11. Atherly, D.E., et al., Projected health and economic impact of rotavirus vaccination in GAVI-eligible countries: 2011-2030. Vaccine, 2012. 30 Suppl 1: p. A7-14.

12. Tate, J.E., et al., Rotavirus disease burden and impact and cost-effectiveness of a rotavirus vaccination program in kenya. J Infect Dis, 2009. 200 Suppl 1: p. S76-84. 
13. van Hoek, A.J., et al., A cost effectiveness and capacity analysis for the introduction of universal rotavirus vaccination in Kenya: comparison between Rotarix and RotaTeq vaccines. PLoS One, 2012. 7(10): p. e47511.

14. Berry, S.A., et al., The cost-effectiveness of rotavirus vaccination in Malawi. J Infect Dis, 2010. 202 Suppl: p. S108-15.

15. Verguet, S., et al., Public finance of rotavirus vaccination in India and Ethiopia: an extended costeffectiveness analysis. Vaccine, 2013. 31(42): p. 4902-10.

16. Abbott, C., et al., Evaluation of cost-effectiveness of live oral pentavalent reassortant rotavirus vaccine introduction in Ghana. Vaccine, 2012. 30(15): p. 2582-7.

17. WHO, WHO SAGE recommendation. Wkly Epidemiol Rec, 2009. 84(23): p. 220-36.

18. PATH. [cited 2014 May 5]; Available from: http://sites.path.org/rotavirusvaccine/rotavirusadvocacy-and-communications-toolkit/country-introduction-maps-and-list/.

19. Aikins, M., et al., Hospital health care cost of diarrheal disease in Northern Ghana. J Infect Dis. 202 Suppl: p. S126-30.

20. MacIntyre, U.E. and F.P. de Villiers, The economic burden of diarrheal disease in a tertiary level hospital, Gauteng, South Africa. J Infect Dis, 2010. 202 Suppl: p. S116-25.

21. Rheingans, R.D., et al., Economic costs of rotavirus gastroenteritis and cost-effectiveness of vaccination in developing countries. J Infect Dis, 2009. 200 Suppl 1: p. S16-27.

22. Rheingans, R., et al., Exploring household economic impacts of childhood diarrheal illnesses in 3 African settings. Clin Infect Dis, 2012. 55 Suppl 4: p. S317-26.

23. Tate, J.E., et al., Disease and economic burden of rotavirus diarrhoea in India. Vaccine, 2009. 27 Suppl 5: p. F18-24.

24. Burke, R.M., et al., The burden of pediatric diarrhea: a cross-sectional study of incurred costs and perceptions of cost among Bolivian families. BMC Public Health, 2013. 13: p. 708. 
25. Jauregui, B., et al., Strengthening the technical capacity at country-level to make informed policy decisions on new vaccine introduction: lessons learned by PAHO's ProVac Initiative. Vaccine, 2011. 29(5): p. 1099-106.

26. Clark, A., et al., TRIVAC decision-support model for evaluating the cost-effectiveness of Haemophilus influenzae type $b$, pneumococcal and rotavirus vaccination. Vaccine, 2013. 31 Suppl 3: p. C19-29.

27. République du Sénégal,Enquête Démographique et de santé à Indicateurs Multiples V(EDS-MICS) 2010-2011,Rapport Final,ANSD, MEASURE DHS, Rapport Final. 520 pages. .

28. République du Sénégal, Ministère de la Santé et de la Prévention,PNDS 2009-2018 Sénégal,version finale, janvier 2009,86 Pages.

29. République du Sénégal, Ministère de l'Economie et des Finances, Agence Nationale de Statistique et de la Démographie, Situation Economique et Sociale du Sénégal en 2010, Rapport final, Décembre 2011359 pages.

30. Bilcke, J., et al., Estimating the incidence of symptomatic rotavirus infections: a systematic review and meta-analysis. PLoS One, 2009. 4(6): p. e6060.

31. Nokes, D.J., et al., Incidence and clinical characteristics of group A rotavirus infections among children admitted to hospital in Kilifi, Kenya. PLoS Med, 2008. 5(7): p. e153.

32. Rheingans, R.D., et al., Economic and health burden of rotavirus gastroenteritis for the 2003 birth cohort in eight Latin American and Caribbean countries. Rev Panam Salud Publica, 2007. 21(4): p. 192-204.

33. Sire, J.M., et al., Community-acquired infectious diarrhoea in children under 5 years of age in Dakar, Senegal. Paediatr Int Child Health, 2013. 33(3): p. 139-44.

34. Sambe-Ba, B., et al., Community-acquired diarrhea among children and adults in urban settings in Senegal: clinical, epidemiological and microbiological aspects. BMC Infect Dis, 2013. 13: p. 580. 
35. Tate, J.E., et al., 2008 estimate of worldwide rotavirus-associated mortality in children younger than 5 years before the introduction of universal rotavirus vaccination programmes: a systematic review and meta-analysis. Lancet Infect Dis, 2011.

36. Mwenda, J.M., et al., African rotavirus surveillance network: a brief overview. Pediatr Infect Dis J, 2014. 33 Suppl 1: p. S6-8.

37. Nitiema, L.W., et al., Burden of rotavirus and other enteropathogens among children with diarrhea in Burkina Faso. Int J Infect Dis, 2011. 15(9): p. e646-52.

38. Liu, L., et al., Global, regional, and national causes of child mortality: an updated systematic analysis for 2010 with time trends since 2000. Lancet, 2012. 379(9832): p. 2151-61.

39. République du Sénégal, Ministère de la Santé et de l'Action Sociale, Direction Générale de la Santé, Direction de la Prévention, Résultats de l'Enquête de Couvertures Vaccinales du PEV, Sénégal, Février 2013, Rapport Final version 21 Mai 2013,73 pages.

40. Madhi, S.A., et al., Effect of human rotavirus vaccine on severe diarrhea in African infants. N Engl J Med, 2010. 362(4): p. 289-98.

41. Patel, M.M., et al., Removing the age restrictions for rotavirus vaccination: a benefit-risk modeling analysis. PLoS Med, 2012. 9(10): p. e1001330.

42. GAVI. [cited 2014 May 5]; Available from: http://www.gavialliance.org/about/governance/programme-policies/co-financing/.

43. Griffiths, U.K., et al., Incremental system costs of introducing combined DTwP-hepatitis B-Hib vaccine into national immunization services in Ethiopia. Vaccine, 2009. 27(9): p. 1426-32.

44. World Health Organization, P., Optimize Senegal Report. 2013. p. 66.

45. Organization, W.H. ChOosing Interventions that Cost-Effective.(WHO-CHOICE). Available from: http://www.who.int/choice/en/. 
46. République du Sénégal, Ministère de la Santé et de la Prévention Médicale (Division de I'Alimentation, de la Nutrition et de la Survie de l'Enfant),Université Cheikh Anta Diop(Groupe Institut de Pédiatrie Sociale et Institut de Population Développement et Santé de la 2008, 101 pages. .

47. CHOosing Interventions that are Cost Effective (WHO-CHOICE), available at http://www.who.int/choice/en/, [accessed 20 May 2014]

48. Sinha, A., et al., Economic burden of acute lower respiratory tract infection in South African

50. Bank, W. GDP Data--Senegal. [cited 2014 May 5]; Available from: children. Paediatr Int Child Health, 2012. 32(2): p. 65-73.

49. Out of pocket expenditure as a percentage of total health expenditure, H.E.I., WHO Global Health Expenditure Database, available at http://apps.who.int/nha/database [accessed 18th September 2013]. http://data.worldbank.org/country/senegal.

51. Chang, W.C., et al., Cost-effectiveness of rotavirus vaccination programs in Taiwan. Vaccine, 2013. 31(46): p. 5458-65.

52. De la Hoz-Restrepo, F., et al., Systematic review of incremental non-vaccine cost estimates used in cost-effectiveness analysis on the introduction of rotavirus and pneumococcal vaccines. Vaccine, 2013. 31 Suppl 3: p. C80-7.

344 53. Esposito, D.H., et al., Projected impact and cost-effectiveness of a rotavirus vaccination program in 345 India, 2008. Clin Infect Dis, 2011. 52(2): p. 171-7. 
346 54. Plosker, G.L., Rotavirus vaccine RIX4414 (Rotarix): a pharmacoeconomic review of its use in the

347 prevention of rotavirus gastroenteritis in developing countries. Pharmacoeconomics, 2011. 29(11):

$348 \quad$ p. 989-1009.

349 
Table 1. Input parameters for estimating disease burden

\begin{tabular}{|c|c|c|c|c|}
\hline \multirow[t]{2}{*}{ Parameter } & \multirow[t]{2}{*}{ Estimate } & \multicolumn{2}{|c|}{ Scenarios } & \multirow[t]{2}{*}{ Source/s } \\
\hline & & Low & High & \\
\hline \multicolumn{5}{|c|}{ Annual incidence per 100,000 aged $1-59 \mathrm{~m}$ : } \\
\hline Rotavirus (non-severe) cases & 7,523 & 6,816 & 8,330 & Assumption, derived from [1-3] \\
\hline Rotavirus (severe) cases & 2427 & 2,184 & 2,670 & Assumption, derived from [1-3] \\
\hline Rotavirus deaths ${ }^{a}$ & 45 & 40 & 50 & {$[4]$} \\
\hline \multicolumn{5}{|c|}{ Disability weight for DALY calculations } \\
\hline Rotavirus (non-severe) cases & 0.12 & - & - & [5] \\
\hline Rotavirus (severe) cases & 0.12 & - & - & [5] \\
\hline \multicolumn{5}{|l|}{ Mean duration of illness (in days) } \\
\hline Rotavirus (non-severe) cases & 6 & - & - & Assumption \\
\hline Rotavirus (severe) cases & 6 & - & - & Assumption \\
\hline \multicolumn{5}{|c|}{ Age distribution of disease cases and deaths } \\
\hline$<3 \mathrm{~m}:$ & $6.6 \%$ & - & - & {$[6,7]$} \\
\hline 3-5m: & $19.4 \%$ & - & - & {$[6,7]$} \\
\hline 6-8m: & $31.9 \%$ & - & - & {$[6,7]$} \\
\hline 9-11m: & $19.8 \%$ & - & - & {$[6,7]$} \\
\hline 12-23m: & $21.8 \%$ & - & - & {$[6,7]$} \\
\hline 24-35m: & $0.5 \%$ & - & - & {$[6,7]$} \\
\hline 36-47m: & $0.0 \%$ & - & - & {$[6,7]$} \\
\hline 48-59m: & $0.0 \%$ & - & - & {$[6,7]$} \\
\hline
\end{tabular}

${ }^{a}$ Derived from diarrheal disease mortality estimates for Senegal. In the absence of vaccination, this ratio is assumed to decline in each successive birth cohort in line with the general trend in mortality among children under age 5 . This is done by assuming that the fraction of deaths under age 5 caused by the disease remains fixed over time. 
Table 2. Input parameters for estimating health service costs (all costs are presented in 2013 US \$)

\begin{tabular}{|c|c|c|c|c|}
\hline \multirow[t]{2}{*}{ Parameter } & \multirow[t]{2}{*}{ Estimate } & \multicolumn{2}{|c|}{ Scenarios } & \multirow[t]{2}{*}{ Source/s } \\
\hline & & Low & High & \\
\hline \multicolumn{5}{|l|}{ OUTPATIENT VISITS } \\
\hline \multicolumn{5}{|c|}{ Government cost per outpatient visit ${ }^{a}$} \\
\hline Rotavirus outpatient visits & $\$ 3.50$ & $\$ 1.75$ & $\$ 5.25$ & [8] \\
\hline \multicolumn{5}{|c|}{ Household cost per outpatient visit ${ }^{\mathrm{b}}$} \\
\hline Rotavirus outpatient visits & $\$ 1.36$ & $\$ 0.68$ & $\$ 2.04$ & Assumption, derived from [8] \\
\hline \multicolumn{5}{|l|}{ INPATIENT ADMISSIONS } \\
\hline \multicolumn{5}{|c|}{ Government cost per inpatient admission $^{c}$} \\
\hline Rotavirus admissions & $\$ 64.50$ & $\$ 32.25$ & $\$ 96.75$ & [8] \\
\hline \multicolumn{5}{|c|}{ Household cost per inpatient admission ${ }^{d}$} \\
\hline Rotavirus admissions & $\$ 33.23$ & $\$ 16.61$ & $\$ 49.84$ & Assumption, derived from [8] \\
\hline
\end{tabular}

${ }^{a}$ Government costs per outpatient visit include all cost components including drugs and diagnostics.

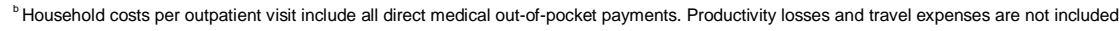

'Government costs per inpatient admission include the cost per bed-day multiplied by the expected length of stay (6 days), and the cost of drugs and diagnostics.

${ }^{\mathrm{a}}$ Household costs per inpatient admission include all direct medical out-of-pocket payments. Productivity losses and travel expenses are not included. 
Table 3. Input parameters for estimating rotavirus vaccine (RV) coverage and timeliness

\begin{tabular}{ccc}
\hline Parameter & Estimate & Source/s \\
\hline $3 m$ & & \\
$6 m$ & $73.4 \%$ & {$[6,9]$} \\
$9 m$ & $88.1 \%$ & {$[6,9]$} \\
$12 m$ & $91.8 \%$ & {$[6,9]$} \\
$24 m$ & $94.7 \%$ & {$[6,9]$} \\
$3 m$ & $96.7 \%$ & {$[6,9]$} \\
$6 m$ & $34.7 \%$ & {$[6,9]$} \\
$9 m$ & $78.5 \%$ & {$[6,9]$} \\
$12 m$ & $85.9 \%$ & {$[6,9]$} \\
$24 m$ & $89.9 \%$ & {$[6,9]$} \\
& $94.7 \%$ & {$[6,9]$} \\
\hline
\end{tabular}


Table 4. Input parameters for estimating RV1 program costs

\begin{tabular}{|c|c|c|c|}
\hline Parameter & Estimate & $\begin{array}{l}\text { Alternate } \\
\text { Scenario }\end{array}$ & Source/s \\
\hline \multicolumn{4}{|l|}{ Vaccine dose price projection } \\
\hline 2015 & $\$ 0.23$ & $\$ 2.38$ & GAVI [10] \\
\hline 2016 & $\$ 0.26$ & $\$ 2.26$ & GAVI [10] \\
\hline 2017 & $\$ 0.30$ & $\$ 2.14$ & GAVI [10] \\
\hline 2018 & $\$ 0.35$ & $\$ 2.04$ & GAVI [10] \\
\hline 2021 & $\$ 0.53$ & $\$ 1.75$ & GAVI [10] \\
\hline 2022 & $\$ 0.61$ & $\$ 1.66$ & GAVI [10] \\
\hline 2023 & $\$ 0.70$ & $\$ 1.58$ & GAVI [10] \\
\hline 2024 & $\$ 1.50$ & $\$ 1.50$ & Assumption \\
\hline 2025 & $\$ 1.50$ & $\$ 1.42$ & Assumption \\
\hline 2026 & $\$ 1.50$ & $\$ 1.35$ & Assumption \\
\hline 2031 & $\$ 1.50$ & $\$ 1.05$ & Assumption \\
\hline 2032 & $\$ 1.50$ & $\$ 0.99$ & Assumption \\
\hline 2033 & $\$ 1.50$ & $\$ 0.94$ & Assumption \\
\hline \multicolumn{4}{|l|}{ Other vaccine dose costs } \\
\hline International handling (\% of vaccine price) & $3 \%$ & -- & Assumption \\
\hline International delivery (\% of vaccine price) & $2 \%$ & -- & Assumption \\
\hline Wastage (\% of doses discarded etc) ${ }^{\mathrm{a}}$ & $5 \%$ & -- & Assumption \\
\hline \multicolumn{4}{|l|}{ Incremental system costs of introduction ${ }^{\mathrm{b}}$} \\
\hline Incremental system cost per dose & $\$ 0.50$ & $\$ 0.35-\$ 1.00$ & {$[11,12]$} \\
\hline
\end{tabular}


Table 5. Input parameters for estimating the health impact of RV1

\begin{tabular}{|c|c|c|c|c|}
\hline \multirow[t]{2}{*}{ Parameter } & \multirow[t]{2}{*}{ Estimate } & \multicolumn{2}{|c|}{ Scenarios } & \multirow[t]{2}{*}{ Source/s } \\
\hline & & Low & High & \\
\hline \multicolumn{5}{|c|}{ Vaccine efficacy vs rotavirus (non-severe) cases } \\
\hline & $47.0 \%$ & $30.0 \%$ & $60.0 \%$ & [13] \\
\hline \multicolumn{5}{|l|}{ Vaccine efficacy vs rotavirus (severe) cases } \\
\hline & $59.0 \%$ & $36.0 \%$ & $74.0 \%$ & [14] \\
\hline \multicolumn{5}{|l|}{ Other vaccination impact assumptions } \\
\hline$\%$ relative coverage ${ }^{a}$ & $94.0 \%$ & $80.0 \%$ & $100 \%$ & Assumption \\
\hline$\%$ decrease in dose efficacy per $\mathrm{yr}^{\mathrm{b}}$ & $28.8 \%$ & $21.6 \%$ & $50.0 \%$ & Assumption \\
\hline$\%$ contribution of herd effect in $<5 y$ rs ${ }^{c}$ & $110 \%$ & $100 \%$ & $120 \%$ & Assumption \\
\hline
\end{tabular}

${ }^{a}$ Relative coverage is the coverage in those at risk of getting the disease (i.e., effective coverage) relative to coverage in the entire birth cohort (i.e., overall coverage). Overall coverage is multiplied by relative coverage to obtain a more realistic estimate of effective coverage.

${ }^{\mathrm{b}}$ To account for waning duration of clinical vaccine-induced protection, TRIVAC uses a waning matrix with age bands $(<3 \mathrm{~m}, 4-5 \mathrm{~m}, 6-8 \mathrm{~m}, 9-11 \mathrm{~m}, 12-23 \mathrm{~m}, 24-35 \mathrm{~m}, 36-$ $47 \mathrm{~m}, 48-59 \mathrm{~m}$ ) repeated in the rows and columns of the matrix. The direct protection at the start of each age band is represented by the diagonal from top-left to bottomright of the matrix. Protection is re-calculated for each age band as the child gets older (moves from left to right in each row). Adjusted protection by age is calculated by adding together the revised protection estimates for each column.

${ }^{\mathrm{C}}$ Rather than endogenous modeling of transmission dynamics, the \% of direct protection for children under 5 yrs is multiplied by a herd effect factor (e.g., $120 \%$ ) to give the $\%$ of total protection in the cohort of interest before age 5 yrs. This excludes any herd effect in individuals aged 5 yrs+ and is therefore very conservative. 
Table 6. Health benefits (20 cohorts vaccinated over the period 2014-2033)

\begin{tabular}{lrrr}
\hline & No vaccine & RV1 & \\
& (Status quo) & With vaccine & \multicolumn{1}{c}{ Averted } \\
\hline Total non-severe cases <5yrs & $\mathbf{3 , 2 8 0 , 9 3 6}$ & $\mathbf{2 , 1 9 4 , 4 8 1}$ & $\mathbf{1 , 0 8 6 , 4 5 5}$ \\
Total severe cases <5yrs & $\mathbf{1 , 0 5 1 , 4 7 6}$ & $\mathbf{6 1 4 , 0 9 2}$ & $\mathbf{4 3 7 , 3 8 4}$ \\
Total deaths <5yrs & $\mathbf{1 5 , 7 7 2}$ & $\mathbf{9 , 1 9 2}$ & $\mathbf{6 , 5 8 0}$ \\
Total deaths<5yrs (undiscounted) & $\mathbf{2 0 , 4 5 6}$ & $\mathbf{1 1 , 9 5 2}$ & $\mathbf{8 , 5 0 3}$ \\
DALYs & $\mathbf{4 5 7 , 4 6 0}$ & $\mathbf{2 6 7 , 1 8 0}$ & $\mathbf{1 9 0 , 2 8 0}$ \\
YLDs - DALYs due to morbidity & 8,470 & 5,490 & 2,980 \\
YLLs - DALYs due to mortality & 448,990 & 261,680 & 187,300 \\
\hline
\end{tabular}

Health benefits are discounted at $3 \%$ per year unless otherwise indicated. 
Table 7. Economic benefits ( 20 cohorts vaccinated over the period 2014-2033)

\begin{tabular}{crrr}
\hline & \multicolumn{1}{c}{ No vaccine } & \multicolumn{1}{l}{$\mathbf{R V 1}$} \\
(status quo) & \multicolumn{1}{l}{ With vaccine } & \multicolumn{1}{c}{ Averted } \\
\hline TOTAL GOV. HEALTH SERVICE COSTS & $\mathbf{\$ 1 8 , 8 4 9 , 1 8 2}$ & $\mathbf{\$ 1 1 , 2 0 8 , 6 0 2}$ & $\mathbf{\$ 7 , 6 4 0 , 5 8 0}$ \\
Total outpatient visit costs & $\$ 3,831,449$ & $\$ 2,437,821$ & $\$ 1,393,628$ \\
$\quad$ Total inpatient admission costs & $\$ 15,017,733$ & $\$ 8,770,781$ & $\$ 6,246,952$ \\
TOTAL SOCIETAL HEALTH SERVICE COSTS & $\mathbf{\$ 2 8 , 0 6 4 , 1 1 5}$ & $\mathbf{\$ 1 6 , 6 6 8 , 2 6 6}$ & $\mathbf{\$ 1 1 , 3 9 5 , 8 4 9}$ \\
$\quad$ Total outpatient visit costs & $\$ 5,309,974$ & $\$ 3,379,203$ & $\$ 1,930,772$ \\
Total inpatient admission costs & $\$ 22,754,141$ & $\$ 13,289,063$ & $\$ 9,465,078$ \\
\hline
\end{tabular}

Costs are discounted at $3 \%$ per year. 
Table 8. Discounted cost-effectiveness of RV (20 cohorts vaccinated over the period 2014-2033)

\begin{tabular}{|c|c|c|}
\hline & \multicolumn{2}{|l|}{ RV1 } \\
\hline & $\begin{array}{l}\text { Government } \\
\text { perspective }\end{array}$ & $\begin{array}{l}\text { Societal } \\
\text { perspective }\end{array}$ \\
\hline \multicolumn{3}{|l|}{ Cost-effectiveness compared to no vaccine } \\
\hline Net cost of vaccine introduction & $\$ 17,570,000$ & $\$ 13,810,000$ \\
\hline Costs of vaccine introduction & $\$ 25,210,000$ & $\$ 25,210,000$ \\
\hline Health service costs avoided & $\$ 7,640,000$ & $\$ 11,400,000$ \\
\hline DALYs averted & 190,280 & 190,280 \\
\hline YLDs averted - DALYS due to morbidity & 2,980 & 2,980 \\
\hline YLLs averted - DALYs due to mortality & 187,300 & 187,300 \\
\hline US\$ per DALY averted & $\$ 92$ & $\$ 73$ \\
\hline \multicolumn{3}{|l|}{ Cost-effectiveness threshold } \\
\hline 1 x GDP per capita (2012) - WHO threshold for 'highly cost-effective' & $\$ 1,032$ & $\$ 1,032$ \\
\hline 3 x GDP per capita (2012) - WHO threshold for 'cost-effective' & $\$ 3,095$ & $\$ 3,095$ \\
\hline
\end{tabular}

Costs and DALYs are discounted at $3 \%$ per year. 
1. Bilcke, J., et al., Estimating the incidence of symptomatic rotavirus infections: a systematic review and meta-analysis. PLoS One, 2009. 4(6): p. e6060.

2. Rheingans, R.D., et al., Economic and health burden of rotavirus gastroenteritis for the 2003 birth cohort in eight Latin American and Caribbean countries. Pan American Journal of Public Health, 2007. 21(4): p. 192-204.

3. Nokes, D.J., et al., Rotavirus genetic diversity, disease association, and temporal change in hospitalized rural Kenyan children. J Infect Dis, 2010. 202 Suppl: p. S180-6.

4. Liu, L., et al., Global, regional, and national causes of child mortality: an updated systematic analysis for 2010 with time trends since 2000. Lancet, 2012. 379(9832): p. 2151-61.

5. Murray, C. and A. Lopez, The global burden of disease: a comprehensive assessment of mortality and disability from diseases, injuries, and risk factors in 1990 and projected to 2020., in Global Burden of Disease and Injury Series Vol. 1 xxxii, 990 p. 1996, School of Public Health, Harvard University. Boston, Massachusetts.

6. Clark, A. and C. Sanderson, Timing of children's vaccinations in 45 low-income and middleincome countries: an analysis of survey data. Lancet, 2009. 373(9674): p. 1543-9.

7. Vaccine Schedules. [cited 20145 May]; Available from: www.vaccine-schedules.com.

8. Country-specific unit costs for health services. [website] 2008 9/7/2011]; Available from: http://www.who.int/choice/country/country-specific/en/index.html.

9. République du Sénégal, Ministère de la Santé et de l'Action Sociale, Direction Générale de la Santé, Direction de la Prévention, Résultats de l'Enquête de Couvertures Vaccinales du PEV, Sénégal, Février 2013,Rapport Final version 21 Mai 2013,73 pages. 10. GAVI. Co-financing policy. [cited 20145 May]; Available from: http://www.gavi.org/about/governance/programme-policies/co-financing/.

11. World Health Organization, P., Optimize Senegal Report. 2013. p. 66.

12. Griffiths, U.K., et al., Incremental system costs of introducing combined DTwP-hepatitis B-Hib vaccine into national immunization services in Ethiopia. Vaccine, 2009. 27(9): p. 1426-32.

13. Atherly, D.E., et al., Projected health and economic impact of rotavirus vaccination in GAVIeligible countries: 2011-2030. Vaccine, 2012. 30 Suppl 1: p. A7-14.

14. Madhi, S.A., et al., Effect of human rotavirus vaccine on severe diarrhea in African infants. N Engl J Med, 2010. 362(4): p. 289-98. 
Figure 1. US\$ per DALY averted for base-case scenario and alternative scenarios: Government perspective and societal perspective

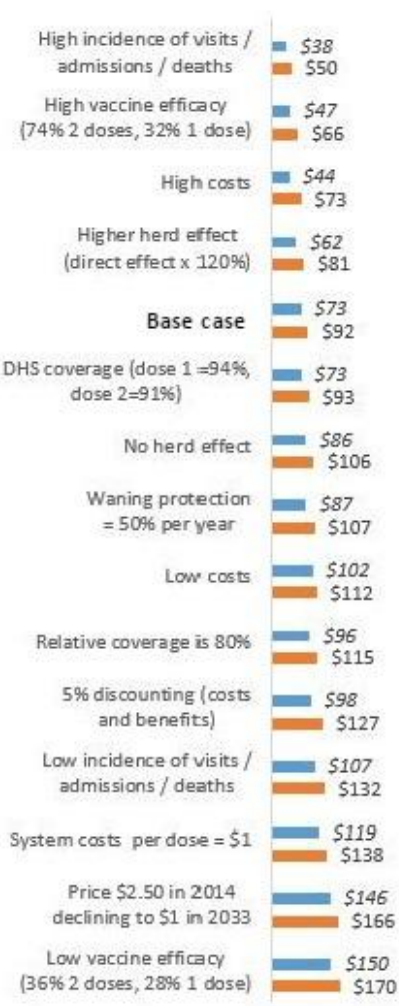

so

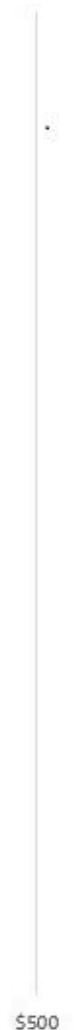

$\$ 500$

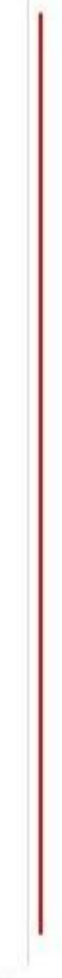

$\$ 1,000$

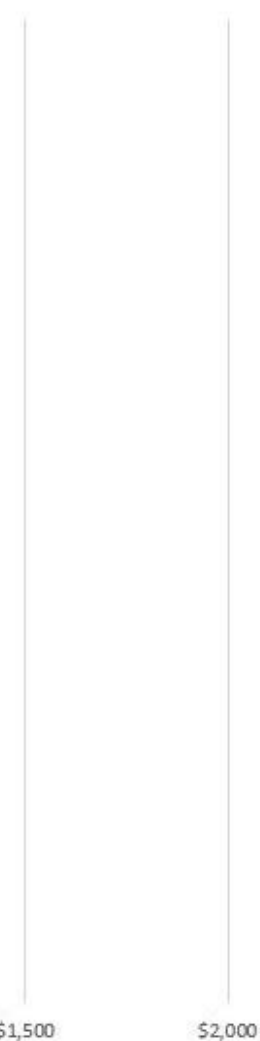

$\$ 2,000$

Societal Perspective

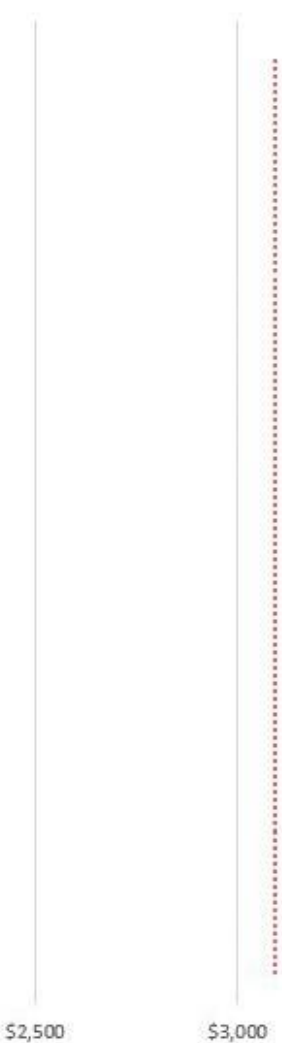

